\title{
Shear Heating in Granular Layers
}

\author{
KAREN MAIR $^{1,2}$ and CHRIS MARONE ${ }^{1}$
}

\begin{abstract}
Heat-flow measurements imply that the San Andreas Fault operates at lower shear stresses than generally predicted from laboratory friction data. This suggests that a dramatic weakening effect or reduced heat production occur during dynamic slip. Numerical studies intimate that grain rolling or localization may cause weakening or reduced heating, however laboratory evidence for these effects are sparse. We directly measure frictional resistance $(\mu)$, shear heating and microstructural evolution with accumulated strain in layers of quartz powder sheared at a range of effective stresses $\left(\sigma_{n}=5-70 \mathrm{MPa}\right)$ and sliding velocities $(V=0.01-10 \mathrm{~mm} / \mathrm{s})$. Tests conducted at $\sigma_{n} \geq 25 \mathrm{MPa}$ show strong evidence for shear localization due to intense grain fracture. In contrast, tests conducted at low effective stress $\left(\sigma_{n}=5 \mathrm{MPa}\right)$ show no preferential fabric development and minimal grain fracture hence we conclude that non-destructive processes such as grain rolling/sliding, distributed throughout the layer, dominate deformation. Temperature measured close to the fault increases systematically with $\sigma_{n}$ and $V$, consistent with a one-dimensional heat-flow solution for frictional heating in a finite width layer. Mechanical results indicate stable sliding $(\mu \sim 0.6)$ for all tests, irrespective of deformation regime, and show no evidence for reduced frictional resistance at rapid slip or high effective stresses. Our measurements verify that the heat production equation $\left(q=\mu \sigma_{n} V\right)$ holds regardless of localization state or fracture regime. Thus, for quasistatic velocities $(V \leq 10 \mathrm{~mm} / \mathrm{s})$ and effective stresses relevant to earthquake rupture, neither grain rolling/sliding or shear localization appear to be a viable mechanism for the dramatic weakening or reduced heating required to explain the heat flow paradox.
\end{abstract}

Key words: Friction, shear heating, fault strength, shear localization, fault gouge.

\section{Introduction}

An enduring paradox in earthquake studies is that the heat flow measured near the San Andreas Fault is much lower than that predicted using stress field, plate velocity and standard laboratory derived friction values (e.g., LACHENBRUCH and SASS, 1980). The heat production equation (1) relates shear heating to the work done due to frictional shear:

$$
q=\tau V=\mu \sigma_{n} V
$$

\footnotetext{
${ }^{1}$ Department of Earth, Atmospheric and Planetary Sciences, Massachusetts Institute of Technology, Cambridge, MA 02139, USA. E-mail: karen@barre.mit.edu cjm@westerly.mit.edu

${ }^{2}$ Now at: Department of Earth Sciences, University of Liverpool, Liverpool, L69 3GP, UK.
} 
where $q$ is rate of heat production per unit area; $\tau$ is shear stress, which during steady sliding equals friction coefficient $(\mu)$ multiplied by effective normal stress $\left(\sigma_{n}\right)$; and $V$ is sliding velocity.

Solutions to this heat-flow debate (summarized in SCHOLZ, 1996, 2000) require a reduction in $q$ and generally invoke mechanisms to reduce fault friction. For example the addition of clays may lubricate the fault zone reducing friction, however, it is unclear whether clays are pervasive in natural fault zones (CHESTER et al., 1993). Alternatively, frictional melting due to high temperatures caused by rapid sliding on the fault may reduce shear stress (MCKENZIE and BRUNE, 1972). SiBSON (1975) argued that pseudotachylytes observed in the field were evidence of this type of frictional melting during seismic slip events.

There is little experimental data to test these hypotheses since few laboratory studies have systematically measured both friction and shear heating over a wide range of conditions. However, melts formed in the laboratory during high velocity frictional sliding were found to: (1) have very low viscosity, which may lubricate fault surfaces (SPRAY, 1993); and (2) be associated with rapid changes in friction (Tsutsumi and Sнimaмoto, 1997). Even below the melting point, temperature may affect the stability and velocity dependence of friction (e.g., STESKY, 1978; LOCKNER et al., 1986; BLANPIED et al., 1995). YoshiokA $(1985,1986)$ and Brown (1998) showed that unstable stick-slip sliding on simulated faults generates less heat than stable sliding, suggesting that different mechanisms may operate in each regime.

Mature fault zones generally contain significant quantities of wear material or gouge. However, previous experimental work (e.g., BlANPIED et al., 1998; Brown, 1998) has mainly concentrated on the shearing of bare surfaces with no gouge. There are very few direct observations of shear heating in granular layers (LOCKNER and OKUBO, 1983), hence this topic clearly warrants further investigation. Numerical experiments of faults containing granular material show low-heat generation compared to faults with no gouge (MORA and PLACE, 1998). This may suggest a dramatic weakening in faults with gouge. MORA and PlACE (1999) show evidence of significant weakening associated with the onset of localized slip in faults with gouge which is mainly attributed to grain rolling. Hence they (MORA and PlACE, 1998) propose that the mechanism for low-heat generation in faults with gouge is rolling and bouncing of grains leading to minimal slip between individual grains. This raises questions regarding the role of localization fabrics in heating and how grain fracture (absent in these numerical simulations) would affect shear heating compared to a non-destructive mechanism such as grain rolling/sliding.

The purpose of this paper is to present new laboratory results investigating shear heating in granular layers as a function of accumulated strain, localization, normal stress and sliding velocity. Results indicate that the heat production equation holds for distributed and localized shear and that for a given value of $q$, heat production is comparable for grain rolling/sliding and grain fracture regimes. 


\section{Experimental Technique}

We shear layers of quartz powder between rough steel surfaces in a servo-controlled direct shear apparatus (Fig. 1). The quartz powder simulates the fault gouge present in mature fault zones. The granular material has an initial grain size of $50-150 \mu \mathrm{m}$ and sub-rounded - angular grains. The rough steel surfaces approximate the boundary conditions of rough rock and inhibit boundary slip.

We apply a uniform normal force to the side blocks, then apply a constant or stepped load point velocity to the middle block. The resulting shear stress, normal stress, shear displacement and layer thickness changes are continuously measured by transducers during deformation. Friction is nominally defined as shear stress

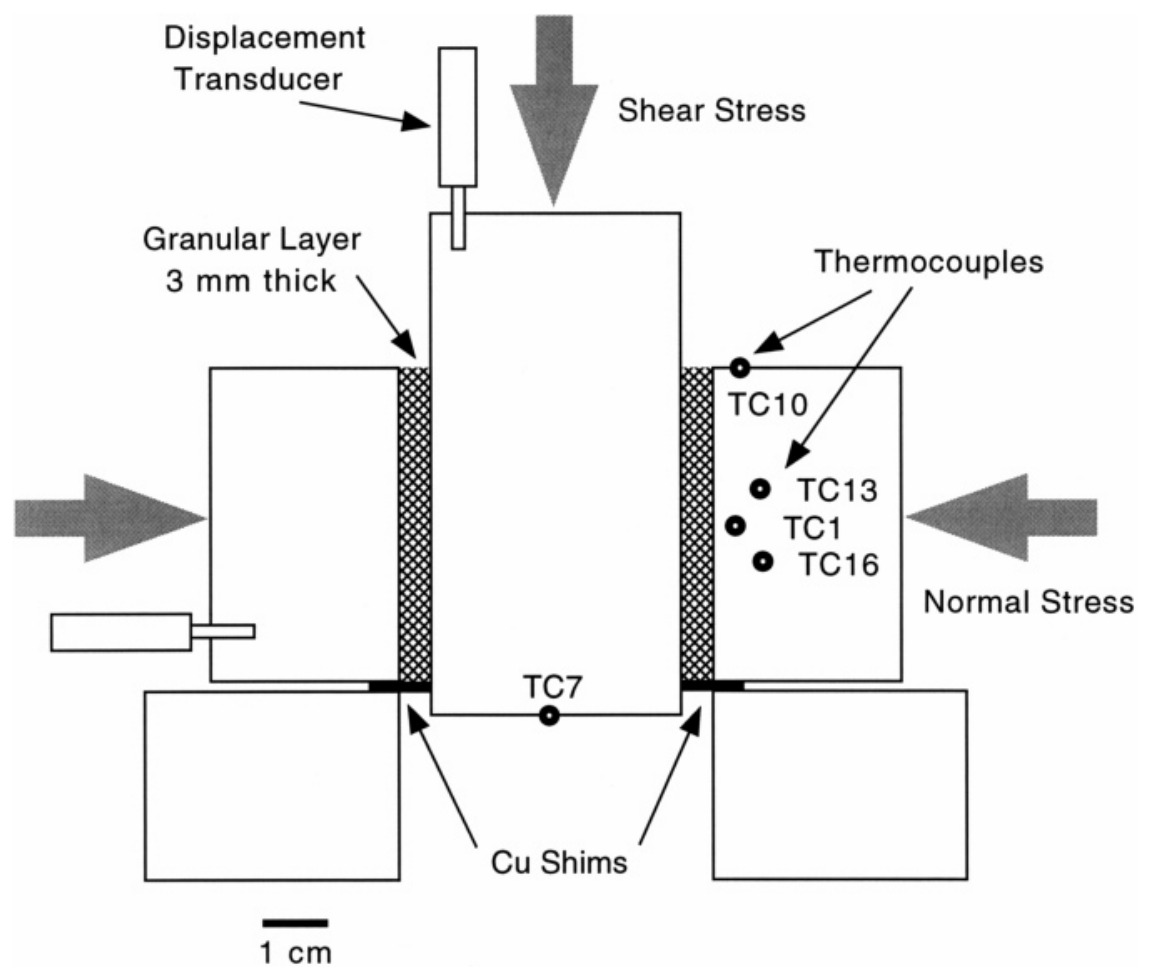

Figure 1

Schematic diagram of the sample geometry illustrating the 3-mm thick granular quartz layers sandwiched between rough steel blocks. Shear and normal stress orientations are indicated and the locations of thermocouples are marked. Three K-type thermocouples (TC1, TC13, TC16) located in blind access holes in one steel side block measure temperature centered on the $50 \times 50 \mathrm{~mm}^{2}$ granular layer at distances $2 \mathrm{~mm}, 6 \mathrm{~mm}, 6 \mathrm{~mm}$ from the center of the layer respectively. Two additional surface thermocouples (TC7, TC10) were attached directly to the center and side blocks, $19.5 \mathrm{~mm}$ and $3 \mathrm{~mm}$ from the center of the granular layer, respectively. Thermocouples are calibrated giving absolute temperatures correct to within $1{ }^{\circ} \mathrm{C}$ and data are generally presented as temperature rise with respect to the initial conditions. 
Table 1

Experiments

\begin{tabular}{llll}
\hline Experiment & $\sigma_{n}, \mathrm{MPa}$ & $V, \mathrm{~mm} / \mathrm{s}$ & $V \sigma_{n}, \times 10^{5} \mathrm{~W} / \mathrm{m}^{2}$ \\
\hline Velocity Stepping & & & \\
$\mathrm{m} 156$ & 25 & $0.3-3$ & - \\
$\mathrm{m} 181$ & 30 & $0.3-3$ & - \\
$\mathrm{m} 147$ & 40 & $0.3-3$ & - \\
$\mathrm{m} 150$ & 40 & $0.3-3$ & - \\
$\mathrm{m} 177$ & 50 & $0.3-3$ & - \\
$\mathrm{m} 178$ & 60 & $0.3-3$ & - \\
$\mathrm{m} 179$ & 70 & $0.3-3$ & - \\
$\mathrm{m} 180$ & 70 & $0.3-3$ & - \\
Constant Velocity & & & \\
$\mathrm{m} 288$ & 5 & 5.0 & 0.25 \\
$\mathrm{~m} 290$ & 5 & 5.0 & 0.25 \\
$\mathrm{~m} 276$ & 25 & 1.0 & 0.25 \\
$\mathrm{~m} 277$ & 25 & 1.0 & 0.25 \\
$\mathrm{~m} 269$ & 25 & 10.0 & 2.5 \\
$\mathrm{~m} 270$ & 25 & 10.0 & 2.5 \\
$\mathrm{~m} 278$ & 25 & 10.0 & 2.5 \\
$\mathrm{~m} 291$ & 50 & 0.5 & 0.25 \\
$\mathrm{~m} 292$ & 50 & 0.5 & 0.25 \\
$\mathrm{~m} 287$ & 50 & 5.0 & 2.5 \\
$\mathrm{~m} 289$ & 50 & 5.0 & 2.5 \\
& & &
\end{tabular}

Initial gouge layer thickness $3 \mathrm{~mm}$.

Shear displacement $20 \mathrm{~mm}$.

$\sigma_{n}=$ Normal stress, $V=$ Velocity.

divided by normal stress. Additional experimental details are given in MAIR and MARONE (1999a). Temperature is measured by multiple sensor locations near the gouge layer to investigate heat conduction through the sample assembly (Fig. 1).

Velocity stepping tests were carried out to investigate the thermal and mechanical response at differing normal stresses. Temperature changes give important information on shear heating, whereas the friction rate parameter indicates fault zone structure and stability. Constant velocity tests were carried out to study the influence of normal stress and sliding velocity on shear heating for a given $V \sigma_{n}$ product. Shear heating was studied for different deformation regimes (e.g., localized versus distributed shear, and fracture versus non-fracture conditions). Experimental conditions covered the following range: $0.001 \leq V \leq 10 \mathrm{~mm} /$ $\mathrm{s} ; 5 \leq \sigma_{n} \leq 70 \mathrm{MPa}$; slip 0-20 $\mathrm{mm}$ (Table 1). All tests were carried out at room temperature and humidity. 


\section{Experimental Results}

\subsection{Deformation of Granular Layers}

The coefficient of friction (shear stress/normal stress) and layer thickness are plotted as a function of shear displacement for a typical high velocity test in Figure 2. Friction increases on initial loading, with some macroscopic strain hardening and then reaches approximately steady state (neutral behavior) after a few millimeters of slip. Second-order perturbations associated with decade step changes in loading velocity are superimposed. At a step increase in velocity, friction shows an abrupt increase and subsequent exponential decay to a new steady state. The converse is observed for a step decrease in velocity. Detailed analyses over a wide range of conditions $\left(0.001 \leq V \leq 10 \mathrm{~mm} / \mathrm{s}, 25 \leq \sigma_{n} \leq 70 \mathrm{MPa}\right)$ indicate that steady-state friction is $\sim 0.6$ after a few mm slip for all tests and yield no evidence for reduced friction at rapid slip or enhanced normal stress (MAIR and MARONE, 1999a). This result applies for the thermal conditions and displacements of our experiments, which overlap with those for which numerical simulations (MORA and Place, 1998) have found dramatic weakening. For larger net slip and greater shear heating, GOLDSBY and TULLIS (1998) have reported dramatic weakening.

The friction rate parameter $(a-b)$ is determined directly from our velocity stepping experiments (see inset to Fig. 3). (a-b) indicates the localization state of the gouge as well as fault zone stability (e.g., MARONE and Kilgore, 1993). All of

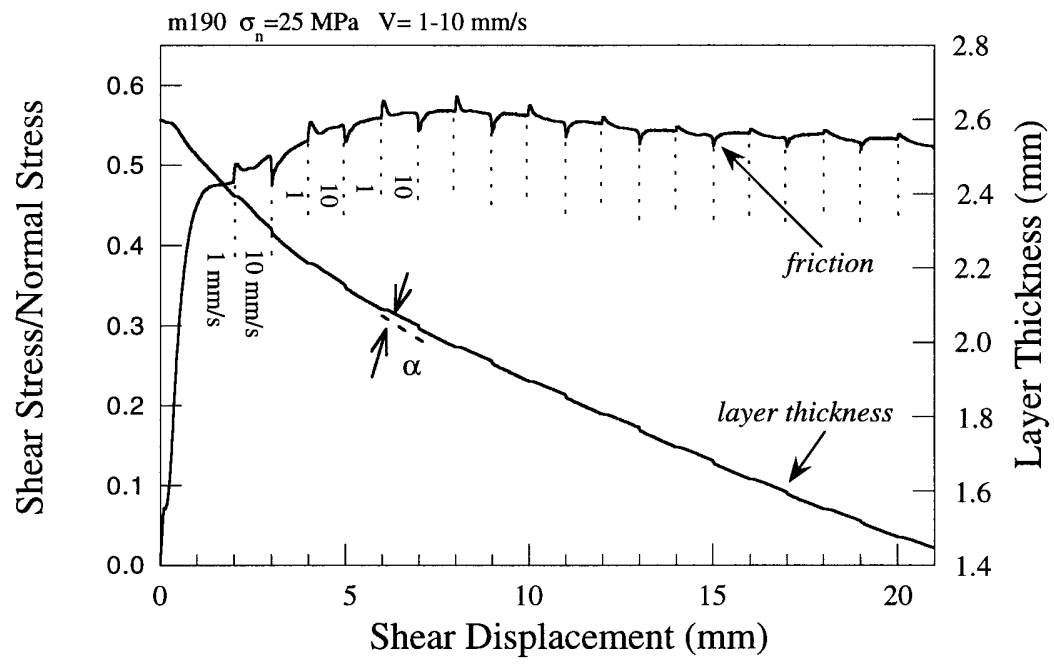

Figure 2

Friction and layer thickness response to step changes in sliding velocity plotted as a function of shear displacement. Velocity steps $(1-10 \mathrm{~mm} / \mathrm{s})$ are indicated as dotted lines and $\sigma_{n}=25 \mathrm{MPa}$. Layer thickness decreases systematically with shear displacement but individual dilation $(\alpha)$ and compaction events associated with velocity steps are seen. 


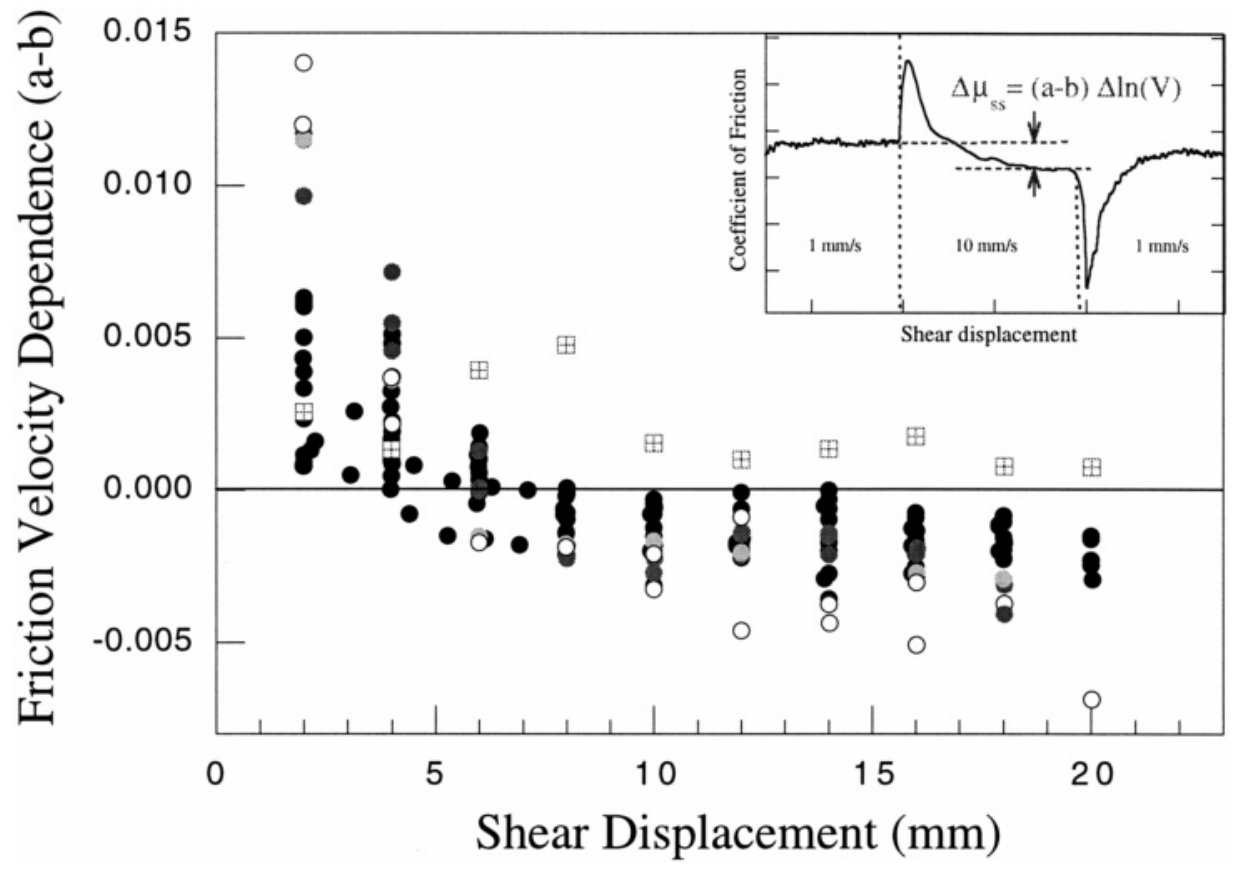

Figure 3

Friction velocity dependence as a function of shear displacement for a range of conditions. Inset shows how $(a-b)$ is measured from a velocity stepping experiment. Black circular markers indicate $\sigma_{n}=25-30$ $\mathrm{MPa}, 0.001 \leq V \leq 10 \mathrm{~mm} / \mathrm{s}$; dark grey circles indicate $\sigma_{n}=40 \mathrm{MPa}$; light grey circular markers indicate $\sigma_{n}=50-60 \mathrm{MPa}$; open circles represent $\sigma_{n}=70 \mathrm{MPa}$ (data replotted from MAIR and MARONE, 1999a). Open square symbols represent new data for $\sigma_{n}=5 \mathrm{MPa}$. Note the transition from velocity strengthening to velocity weakening in all tests except those carried out at $5 \mathrm{MPa}$ where velocity strengthening persists throughout the test.

our tests (with the exception of the $\sigma_{n}=5 \mathrm{MPa}$ experiment) undergo a gradual transition from velocity strengthening $(a-b>0)$ to velocity weakening $(a-b<0)$ with accumulated slip (Fig. 3). This is interpreted as a transition from distributed to localized shear at $\sim 5-10 \mathrm{~mm}$ slip (MARONE, 1998). Previous work indicates that sliding velocity $(0.001 \leq V \leq 10 \mathrm{~mm} / \mathrm{s})$ has little systematic influence on $(a-b)$, however higher normal stress systematically increases both initial strengthening and subsequent weakening by a small amount (MAIR and MARONE, 1999a). The test carried out at $\sigma_{n}=5 \mathrm{MPa}$ shows distinctly different behavior, with velocity strengthening, interpreted as distributed shear, persisting throughout the entire experiment.

Direct (SEM) observations of granular layers deformed at low normal stress $\left(\sigma_{n}=5 \mathrm{MPa} ; V=5 \mathrm{~mm} / \mathrm{s}\right)$ for $20 \mathrm{~mm}$ slip show little or no grain size reduction with respect to the starting powder and no fabric can be identified (Fig. 4a). In contrast, initially identical layers subjected to a higher normal stress $\left(\sigma_{n}=50 \mathrm{MPa} ; V=0.5\right.$ $\mathrm{mm} / \mathrm{s}$ ) and $20 \mathrm{~mm}$ slip show distinct fabric development highlighted by oblique 


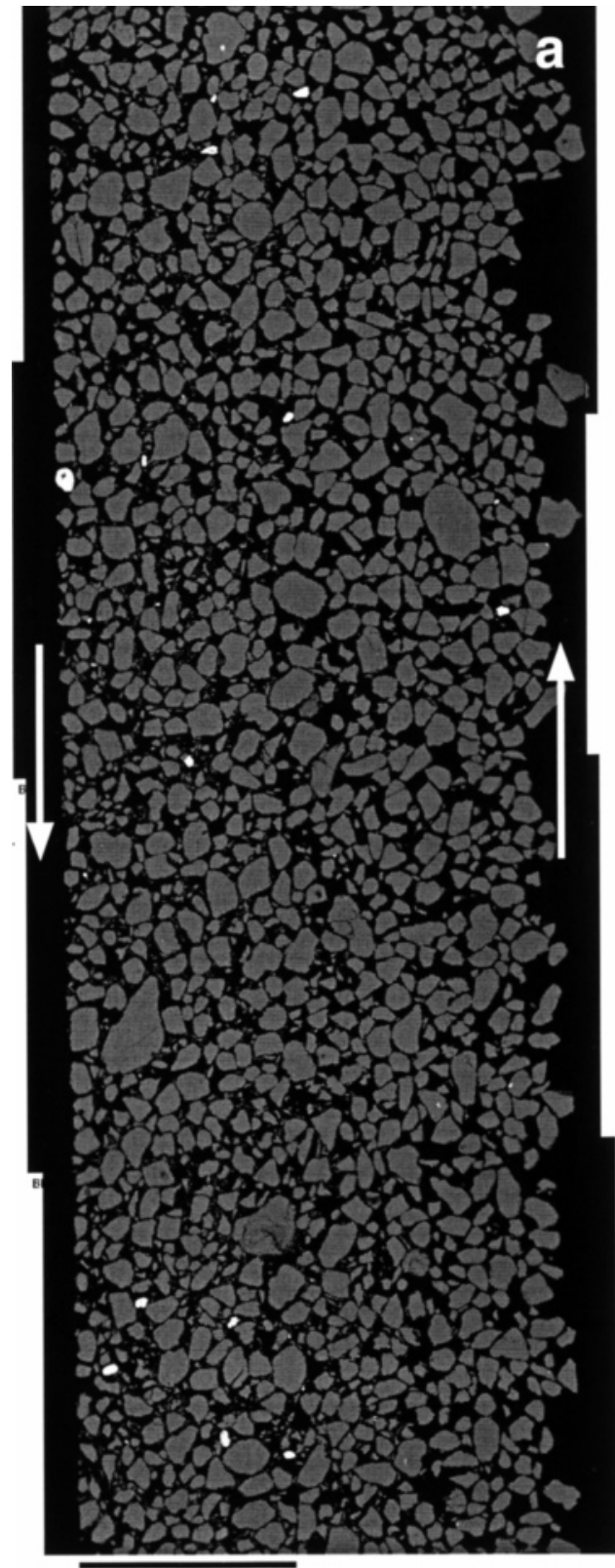

$1 \mathrm{~mm}$

\section{(1)}

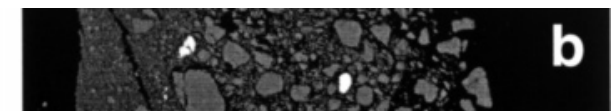

0
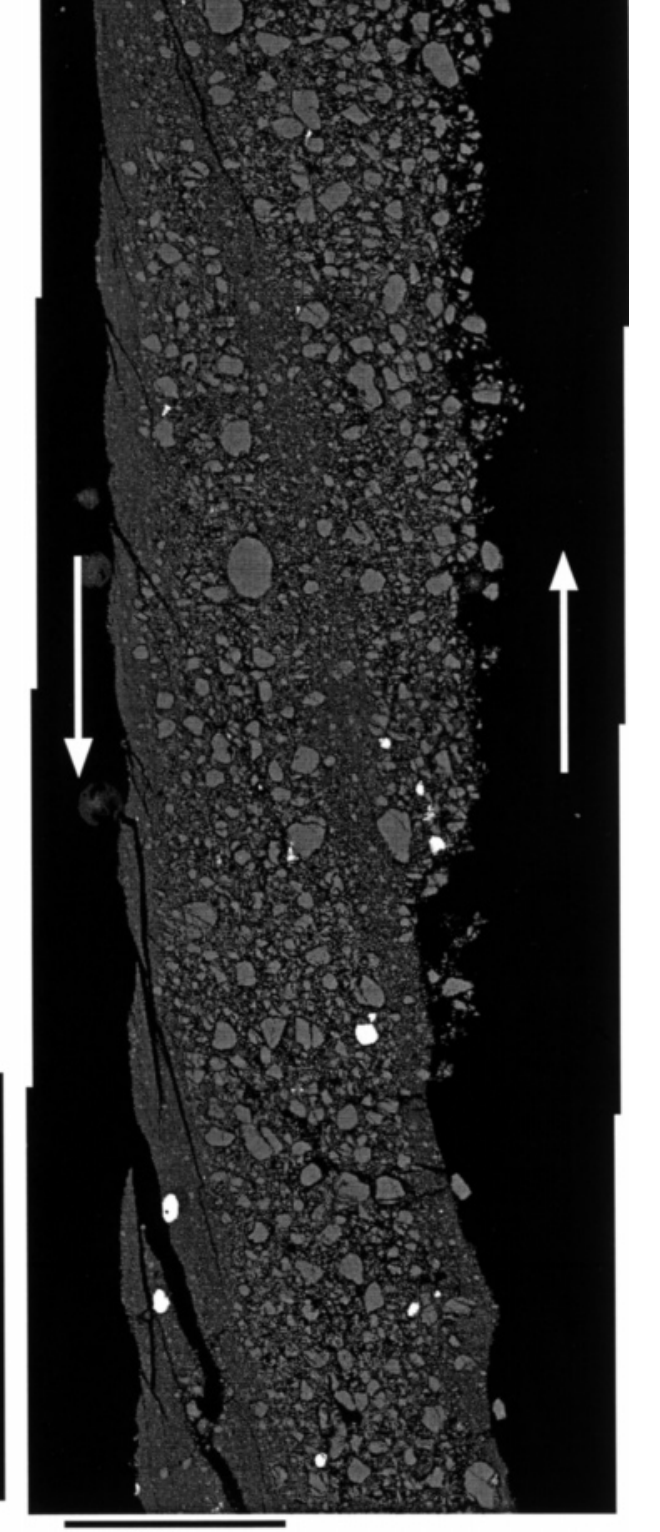

$1 \mathrm{~mm}$

Figure 4

SEM photomicrographs of initially identical granular quartz layers deformed under different conditions: a) $\sigma_{n}=5 \mathrm{MPa}, V=5 \mathrm{~mm} / \mathrm{s}$, slip $=20 \mathrm{~mm} / \mathrm{s}$, b) $\sigma_{n}=50 \mathrm{MPa}, V=0.5 \mathrm{~mm} / \mathrm{s}$, slip $=20 \mathrm{~mm}$. The sense of shear is indicated by arrows. Note the intense grain size reduction and development of heterogeneous fabric in b) which is not apparent in a). Both layers were originally $3 \mathrm{~mm}$ thick hence layer thinning is clearly enhanced at high $\sigma_{n}$. 
strands of intense grain size reduction (Fig. 4b). Clearly, significant comminution of grains has occurred at $\sigma_{n}=50 \mathrm{MPa}$, whereas almost no grain fracture has ensued at $\sigma_{n}=5 \mathrm{MPa}$. We suggest from these observations that deformation at 'high' normal stress $\left(\sigma_{n} \geq 25 \mathrm{MPa}\right)$ is achieved mainly through grain fracture whereas the dominant deformation mechanism at 'low' normal stresses $\left(\sigma_{n}=5 \mathrm{MPa}\right)$ is a non-destructive process such as grain rolling or sliding. Moreover 'high' and 'low' normal stresses result in highly localized and homogeneously distributed shear respectively, consistent with the interpretations of friction velocity dependence (Fig. $3)$.

MAIR and MARONE (1999b) studied progressive deformation as a function of accumulated slip for identical tests conducted at 'high' normal stresses $\left(25 \leq \sigma_{n} \leq 70\right.$ $\mathrm{MPa}$ ) revealing the following. At $5 \mathrm{~mm}$ slip (i.e., within the velocity strengthening regime, Fig. 3), shear is distributed homogeneously throughout the granular layer whereas at $20 \mathrm{~mm}$ slip (i.e., the velocity weakening regime, Fig. 3) distinct fabrics highlighted by grain size reduction have developed indicating the transition to localized shear. This independent observation is consistent with the interpretation given above for the transition in friction velocity dependence.

The microstructural and mechanical observations correlate well, therefore we can study the influence of different deformation regimes and localization state on shear heating by comparing data from tests conducted at 'high' $\left(\sigma_{n} \geq 25 \mathrm{MPa}\right)$ and 'low' $\left(\sigma_{n}=5 \mathrm{MPa}\right)$ normal stresses.

\subsection{Heat Production}

From equation (1) it is clear that heat production $(q)$ should be affected by changes in applied normal stress or sliding velocity. We test this theory by independently varying sliding velocity and normal stress, focussing on two cases where the product $V \sigma_{n}$ is equal to $2.5 \times 10^{5} \mathrm{~W} / \mathrm{m}^{2}$ and $0.25 \times 10^{5} \mathrm{~W} / \mathrm{m}^{2}$, respectively. Figure 5 shows heat production $(q)$ due to frictional heating (calculated as the product of shear stress and sliding velocity $(\tau V)$ measured during constant velocity tests) as a function of shear displacement. After the first few $\mathrm{mm}$ of slip, the frictional work done $(q)$ is comparable for tests with different sliding velocities and normal stresses but the same product $\left(V \sigma_{n}\right)$. Two levels of 'steady-state' heat production, equal to $1.4 \times 10^{5}$ and $0.14 \times 10^{5} \mathrm{~W} / \mathrm{m}^{2}$, are associated with the two cases examined.

From section 3.1 we know that the deformation regime and degree of localization depend strongly on normal stress. By altering the normal stress we can study the non-fracture $(5 \mathrm{MPa})$ and fracture $(50 \mathrm{MPa})$ regimes. We can isolate the influence of deformation regime on shear heating (Table 1; Fig. 5) by varying normal stress $(5,50 \mathrm{MPa})$ and velocity $(5,0.5 \mathrm{~mm} / \mathrm{s})$ in a complementary way, such that the product remains constant (i.e., $\sigma_{n} V=0.25 \times 10^{5} \mathrm{~W} / \mathrm{m}^{2}$ ), hence the work done is the same for both regimes. An important observation (Fig. 5) is that heat 


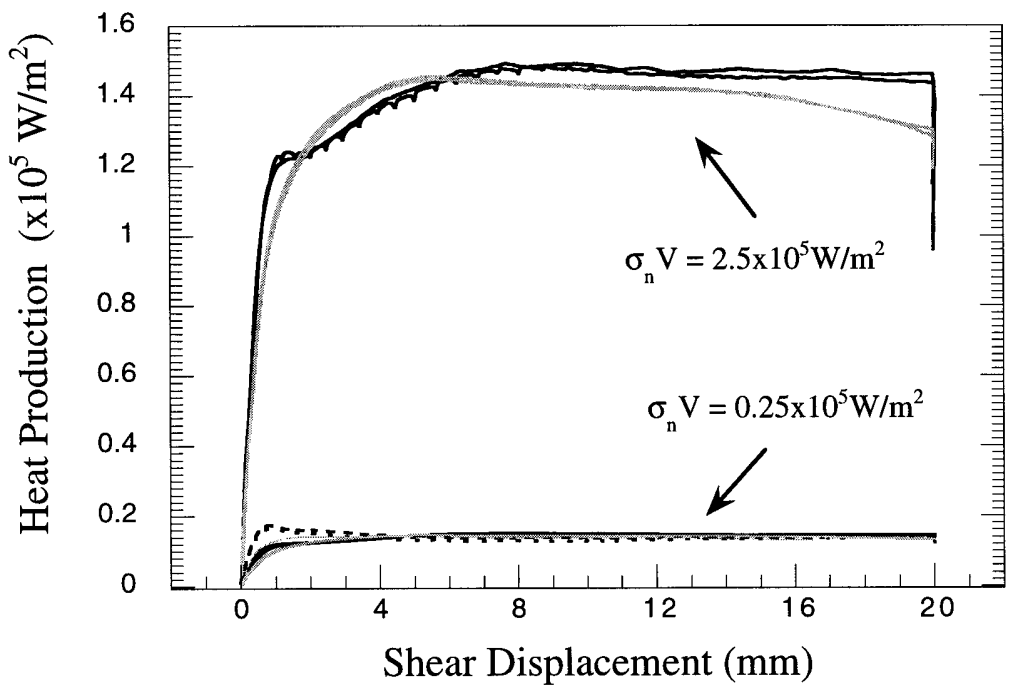

Figure 5

Heat production $q(=\tau V)$ versus shear displacement for a range of tests. Dotted lines indicate $\sigma_{n}=5$ $\mathrm{MPa}$; black solid lines $\sigma_{n}=25 \mathrm{MPa}$; grey lines $\sigma_{n}=50 \mathrm{MPa}$. Sliding velocity is varied in a complementary way to give $V \sigma_{n}=2.5 \times 10^{5} \mathrm{~W} / \mathrm{m}^{2}$ or $0.25 \times 10^{5} \mathrm{~W} / \mathrm{m}^{2}$ (see Table 1). After a few $\mathrm{mm}$ slip, heat production $q$ is comparable for a given product irrespective of the individual values of $V$ or $\sigma_{n}$.

production is similar for the fracture and non-fracture regimes. In the next section we will directly measure the temperature rise produced and thereby test if the heat production equation holds for all our tests.

\subsection{Temperature Measurements: Velocity Stepping Tests}

Temperature change is monitored throughout the tests to reveal temperature signals associated with differing heat production. In Figure 6, temperature change measured at thermocouple TC1 is plotted as a function of shear displacement where velocity is stepped between $0.3-3 \mathrm{~mm} / \mathrm{s}$ and $\sigma_{n}=25-70 \mathrm{MPa}$. The overall trend shows temperature increasing with accumulated slip, consistent with continual shear heating throughout the test. There is a positive relation between the overall temperature rise and increasing normal stress.

Superimposed onto these are smaller temperature excursions associated with individual step changes in loading velocity $(0.3-3 \mathrm{~mm} / \mathrm{s})$. The increase in temperature is greater and more rapid at higher velocity, consistent with the enhanced heat production at higher velocity described by equation (1). The temperature changes lag behind the velocity perturbations due to thermal inertia, finite diffusivity, and the distance between the fault zone and the thermocouple. This explains why the rapid increase in temperature associated with the faster (shaded) velocity reaches the sensor during the subsequent low velocity (unshaded) part. The rate of 


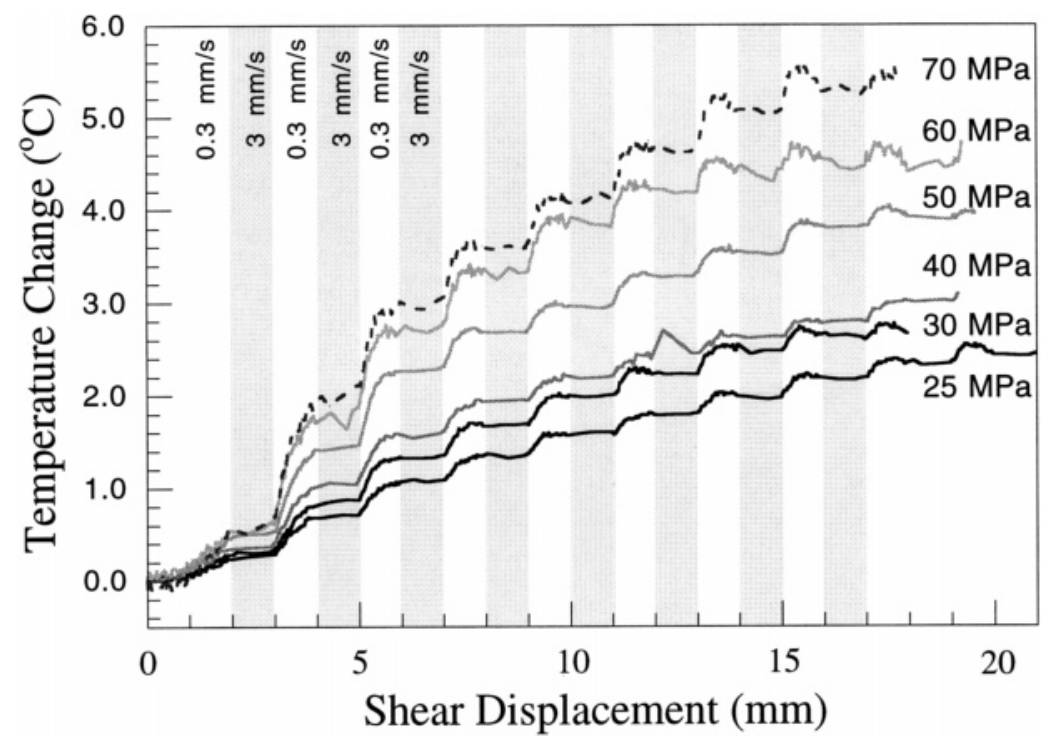

Figure 6

Temperature change (measured at TC1) as a function of shear displacement for velocity stepping tests where $\sigma_{n}$ ranges between $25-70 \mathrm{MPa}$ and velocity is stepped between $0.3-3 \mathrm{~mm} / \mathrm{s}$. High velocity periods are indicated by the shaded regions. Temperature perturbations lag the associated velocity steps. Note the effects of both normal stress and velocity perturbations on temperature change.

temperature rise (the slope of the perturbations) systematically increases with normal stress, consistent with results from bare surface experiments (BRown, 1998). At any specific shear displacement, the temperature rise observed is systematically larger at higher normal stress. This is anticipated from equation (1) due to the enhanced heat production at high $\sigma_{n}$. For a given test, the temperature rise associated with an individual velocity step is largest at the beginning of the test and gradually decreases in size with increasing slip. A related observation is made for the cooling associated with a step down in velocity. Initially, heating is larger than cooling even during the slow velocity periods, however with additional slip, the heating decreases until net cooling during the slow steps is observed. This effect is enhanced at high normal stress.

\subsection{Temperature Measurements: Constant Velocity Tests}

Recognizing that the influences of individual velocity steps may be difficult to decompose we evaluate a simpler case, where $V$ is constant throughout the test. Temperature is monitored simultaneously at several locations in order to determine heat conduction in the sample setup and to constrain modelling parameters for the heat-flow solution presented later. In these tests, we vary normal stress and velocity in a complementary manner such that the product is constant, focussing on two 
cases $V \sigma_{n}=2.5 \times 10^{5} \mathrm{~W} / \mathrm{m}^{2}$ and $V \sigma_{n}=0.25 \times 10^{5} \mathrm{~W} / \mathrm{m}^{2}$. We see from Figure 5, that heat production $(q)$ for a constant $V \sigma_{n}$ product is comparable. Therefore, we can independently study the influence of normal stress and sliding velocity on temperature change for a given value of $q$ (Table 1).

In Figure 7, temperature change is plotted as a function of time where conditions are as follows: a) $V=5 \mathrm{~mm} / \mathrm{s}, \sigma_{n}=50 \mathrm{MPa}$; b) $V=10 \mathrm{~mm} / \mathrm{s}, \sigma_{n}=25$ $\mathrm{MPa}$. Figure 8 shows two additional cases: a) $V=1 \mathrm{~mm} / \mathrm{s}, \sigma_{n}=25 \mathrm{MPa}$; and b) $V=5 \mathrm{~mm} / \mathrm{s}, \sigma_{n}=5 \mathrm{MPa}$.

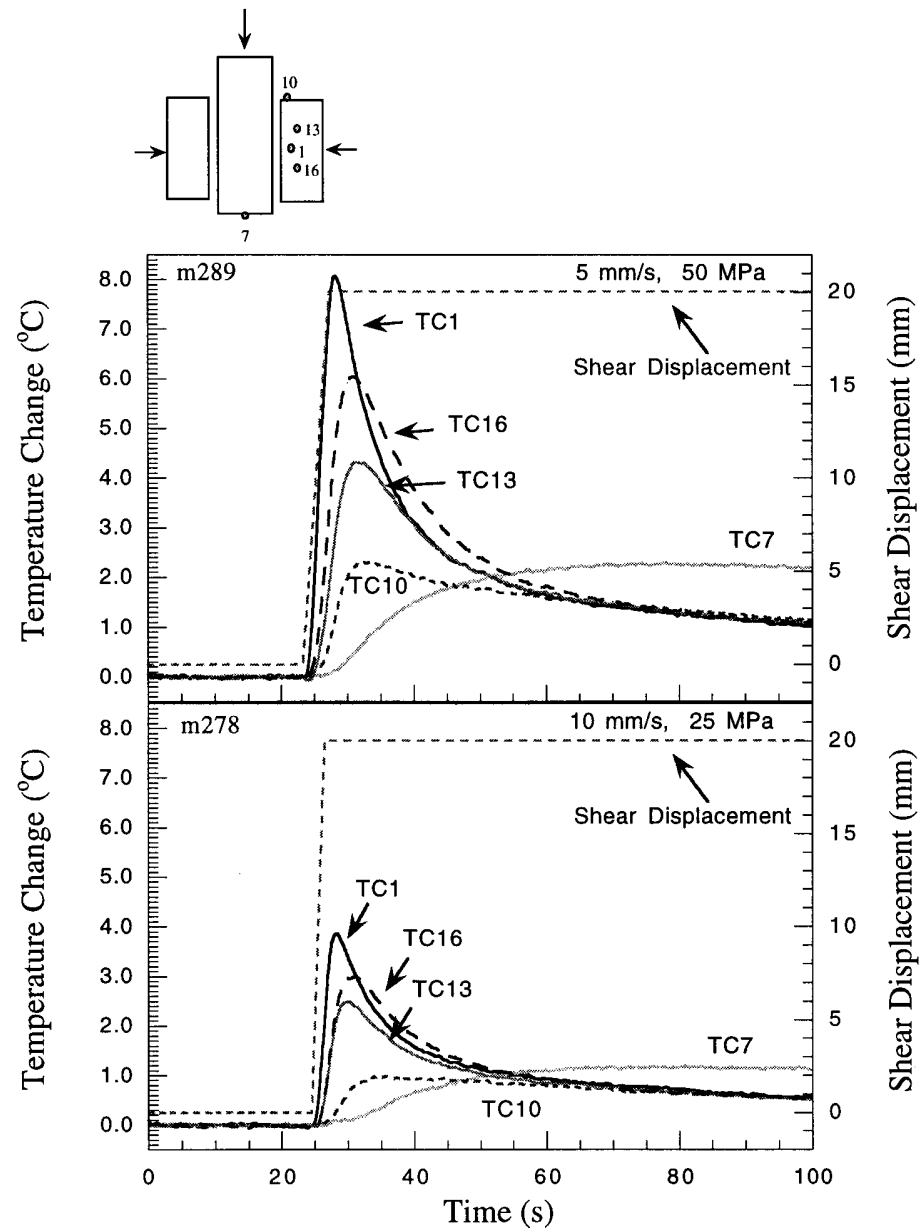

(a)

(b)

Figure 7

Temperature change measured at different sensor locations as a function of time for constant velocity tests where velocity and normal stress are: a) $V=5 \mathrm{~mm} / \mathrm{s}, \sigma_{n}=50 \mathrm{MPa}$; b) $V=10 \mathrm{~mm} / \mathrm{s}, \sigma_{n}=25 \mathrm{MPa}$. $V \sigma_{n}=2.5 \times 10^{5} \mathrm{~W} / \mathrm{m}^{2}$ in both cases. Shear displacement is also plotted (dotted line) as a function of time. Thermocouple locations, shown in subplot, clearly show the significance of heat conduction through the sample. Sliding velocity strongly influences the rate of heating. 


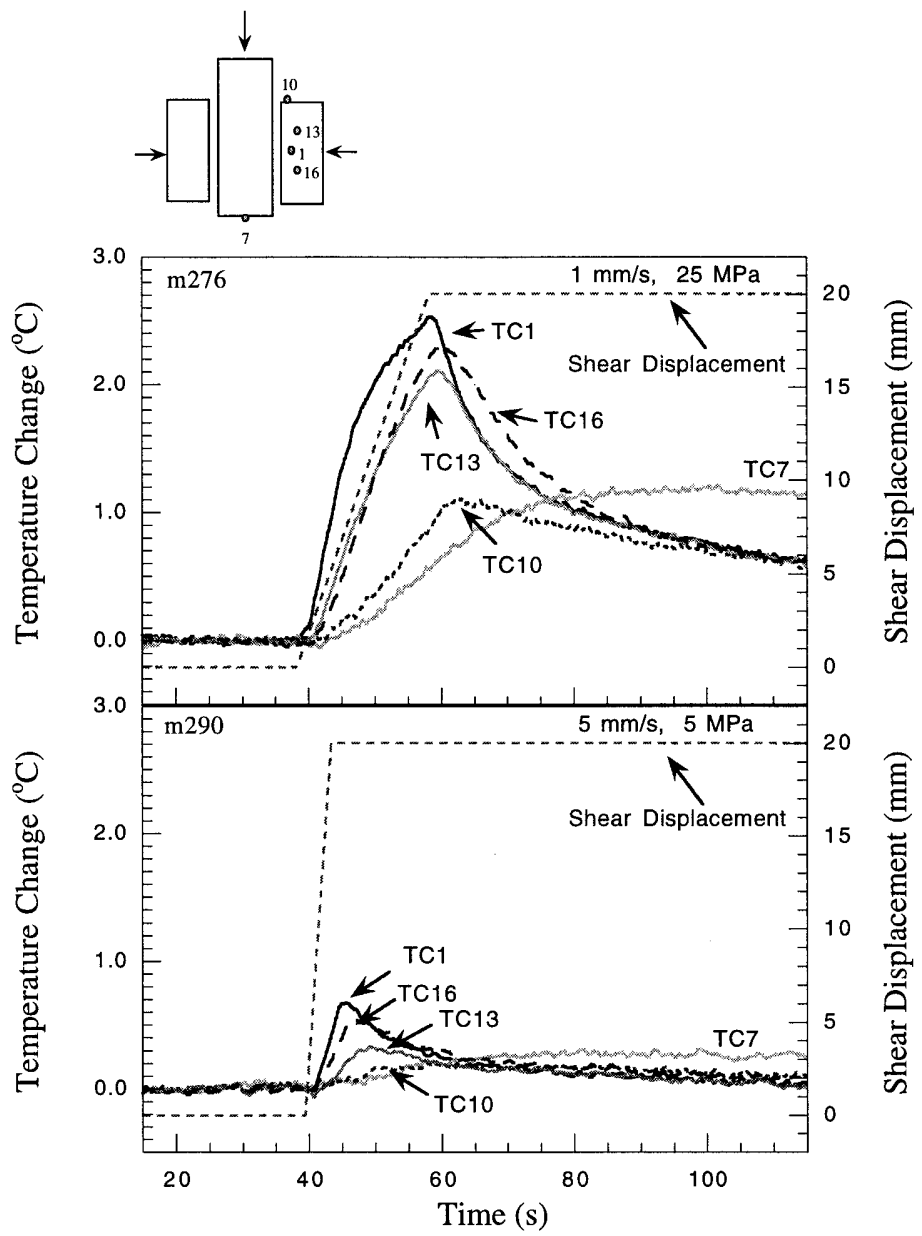

(a)

Figure 8

Temperature change as a function of time for constant velocity tests where velocity and normal stress are: a) $V=1 \mathrm{~mm} / \mathrm{s}$ at $\sigma_{n}=25 \mathrm{MPa}$; and b) $V=5 \mathrm{~mm} / \mathrm{s}, \sigma_{n}=5 \mathrm{MPa}$. $V \sigma_{n}=0.25 \times 10^{5} \mathrm{~W} / \mathrm{m}^{2}$ in both cases. Details are as in Figure 7 but note the change in vertical scale.

The main aspects of all four cases in Figures 7 and 8 are similar. All show a rapid (though nonlinear) increase in temperature of a few ${ }^{\circ} \mathrm{C}$ throughout the heating stage then rapid cooling when shearing ceases. Thermocouples farther from the granular layer have smaller temperature rises and peak temperature is achieved after a longer time interval consistent with expectations from thermal diffusion. An interesting observation is that the temperature rise at TC16 always exceeds that measured at TC13 although the thermocouples are the same distance from the fault zone. This is because the bottom of the middle block that has already participated in shearing is hotter than the top section that has not. As the middle block moves down it carries heat with it hence TC16 is hotter than TC13. Another point is that 
TC7 eventually reaches higher temperatures than TC10 despite being farther from the source. Here we must invoke the contribution from the second layer. TC7, located equidistant from both fault zones, receives heat of the same amplitude at the same time from both layers. In contrast, the other sensors receive heat of different amplitudes from both layers at different times and hence the contribution of the second layer is generally delayed and significantly smaller.

The different values of heat productions in Figures 7 and 8 influence the temperature rise (note the change in scale). For a given heat production (i.e., Fig. 7 or 8 , respectively), the rate of temperature rise is influenced by sliding velocity (i.e., plot a or b). Although the heat production is essentially comparable in a) and b), in each figure, the peak temperature change is larger in the lower velocity tests in each case. This is due to the finite time required for thermal diffusion through the sample. In the faster tests the duration of heating and hence the length of a test is shorter than the diffusion time required for the heat pulse to reach the sensor. Hence the peak temperature is apparently low. This effect is discussed below.

In summary, the total temperature rise for $20 \mathrm{~mm}$ slip (measured at TC1) is plotted versus normal stress in Figure 9. This plot highlights the influence of both normal stress and sliding velocity. Note in particular that an increase in normal

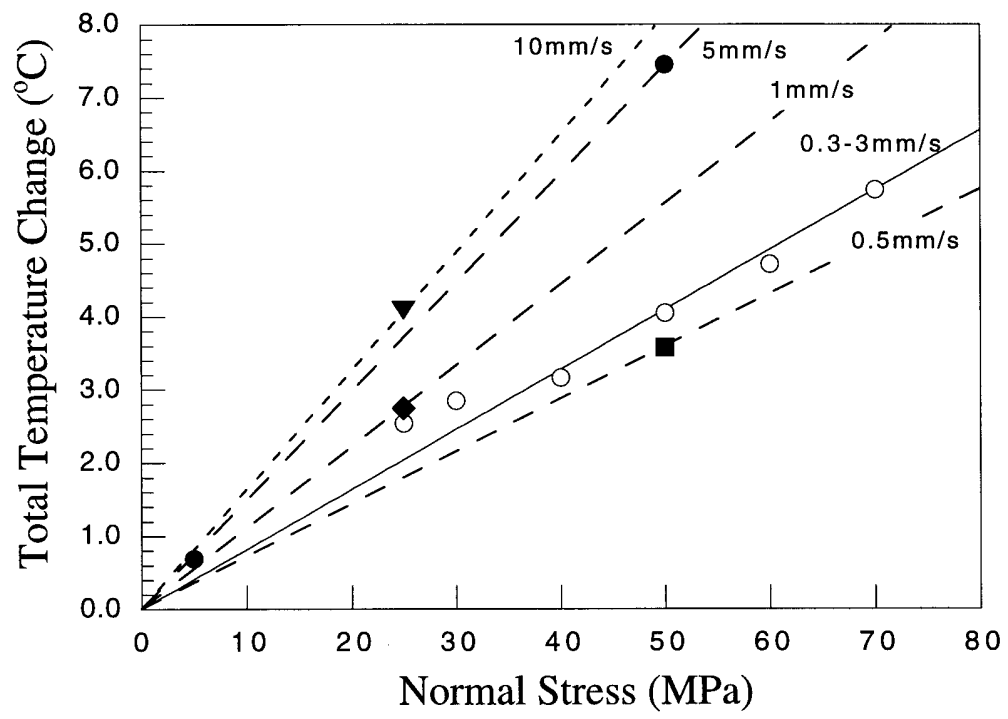

Figure 9

Total temperature change after $20 \mathrm{~mm}$ slip versus applied normal stress for both velocity stepping and constant velocity tests. All the data are measured at TC1. The solid line is best-fit regression to data (indicated by open circles) from test at range of $\sigma_{n}$ between $25-70 \mathrm{MPa}$ and $V=0.3-3 \mathrm{~mm} / \mathrm{s}$. Solid line is forced to cut origin since temperature rise will be zero for zero heat production. Other markers show total temperature change after $20 \mathrm{~mm}$ slip for a range of constant velocity tests. Dotted lines are visual guides linking data for a given velocity and the origin. Velocity conditions are marked. A systematic temperature increase is observed as a function of both increasing normal stress and velocity. 
stress shown by open circles gives a linear increase in temperature. An increase in velocity yields a systematic although not linear increase in temperature. This is due to the finite time required for thermal diffusion.

\section{Heat-flow Solution}

\subsection{Method}

We use a 1-D heat-flow solution for frictional heating in a layer of finite thickness to investigate the variation in shear heating predicted for the conditions of our tests. The equation governing 1-D unsteady transport of heat can be written:

$$
\frac{\partial T}{\partial t}=\frac{Q(x, t)}{\rho C}+\kappa \frac{\partial^{2} T}{\partial x^{2}}
$$

where $T$ is temperature; $t$ is time; $\rho$ is density; $C$ is specific heat; $Q$ is the rate of heat generation per unit volume (i.e., $Q=q / w) ; \kappa=k / \rho C$ is thermal diffusivity where $k$ is thermal conductivity; and $x$ is distance. Equation (2) indicates that the rate of temperature increase at a distance $x$ away from the source is a balance between a heat production term and a heat conduction term. We solve for temperature using the approach of CARDWELL et al. (1978) who consider that heating is uniform over a fault of finite width $w$ :

$$
\begin{aligned}
Q\left(x_{0}, t_{0}\right) & =\frac{\sigma_{f} D}{w s}\left[H\left(x_{0}+\frac{w}{2}\right)-H\left(x_{0}-\frac{w}{2}\right)\right], & & 0<t_{0}<s \\
& =0, & & t_{0}<0, t_{0}>s .
\end{aligned}
$$

In equation (3), $\sigma_{f}$ is frictional stress on the fault; $D$ is fault displacement; $s$ is slip duration; and $H$ is the Heavyside step function. We assume that granular layer thickness $(w / 2=1 \mathrm{~mm})$ is constant throughout the test and that temperature change is averaged over this entire layer. We choose material constants $(k=9.3$ $\left.\mathrm{W} /(\mathrm{m} \cdot \mathrm{C}) ; \kappa=7.8 \times 10^{-7} \mathrm{~mm}^{2} / \mathrm{s}\right)$ which lie between tabulated values for steel and sandstone and give the best fit to our experimental data. Heat production is calculated from equation (3) using our measured values of friction $(\mu=0.6)$, normal stress $\left(\sigma_{n}\right)$, distance from the center of the fault zone $(x)$ and velocity $(V)$ (Table 2). Simulations are designed to reproduce the conditions of our experiments (Figs. 6, 7,8 ) and yield temperature change as a function of time (or slip).

\subsection{Simulation Results}

Simulations were run duplicating the range of stress conditions and velocity stepping histories of the data presented in Figure 6. The temperature rise $2 \mathrm{~mm}$ from the center of the layer (i.e., the position of $\mathrm{TC} 1$ ) is plotted as a function of 
Table 2

1-D shear heating simulations

\begin{tabular}{llll}
\hline$V, \mathrm{~mm} / \mathrm{s}$ & $\sigma_{n}, \mathrm{MPa}$ & $x, \mathrm{~mm}$ & $t, \mathrm{~s}$ \\
\hline $0.3-3$ & 25 & 2 & 29 \\
$0.3-3$ & 50 & 2 & 29 \\
$0.3-3$ & 70 & 2 & 29 \\
0.5 & 50 & 2 & 40 \\
1 & 25 & 2 & 20 \\
5 & 5 & 2 & 4 \\
5 & 50 & 2 & 4 \\
10 & 25 & 0 & 2 \\
10 & 25 & 2 & 2 \\
10 & 25 & 3 & 2 \\
10 & 25 & 4 & 2 \\
10 & 25 & 6 & 2 \\
\hline
\end{tabular}

$x$ is the distance from center of the fault zone (i.e., the heat source) to the sensor.

One dimensional heat flow solution: $\kappa=7.8 \mathrm{e}-7, \mathrm{k}=9.3, \mathrm{x}=2 \mathrm{~mm}$

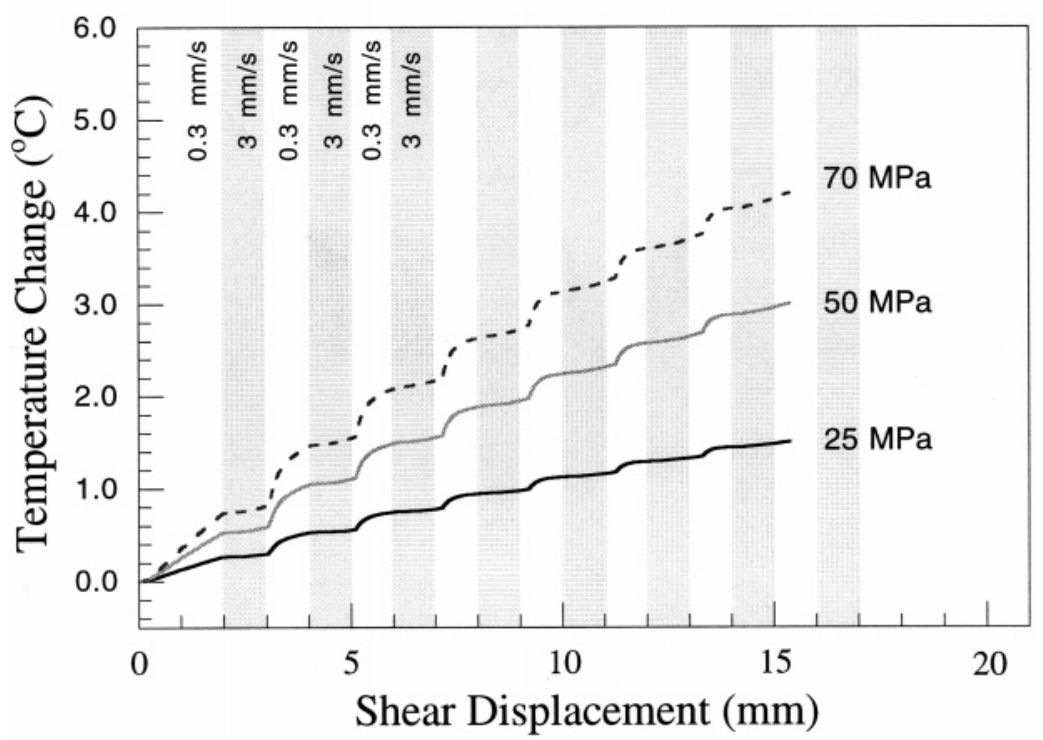

Figure 10

One-dimensional heat-flow solution showing temperature (associated with step changes in heat production) versus shear displacement. Conditions are $V=0.3-3 \mathrm{~mm} / \mathrm{s}, \sigma_{n}=25,50,70 \mathrm{MPa}$. Temperature change is calculated $2 \mathrm{~mm}$ from the center of the fault zone. The high velocity periods are indicated by the shading. Note the overall influence of normal stress and also how the shape of the temperature perturbations changes with increasing slip. The thermal properties used in the simulation are indicated in the text. 
One dimensional heat flow solution: $\kappa=7.8 \mathrm{e}-7, \mathrm{k}=9.3, \mathrm{x}=0-6 \mathrm{~mm}$

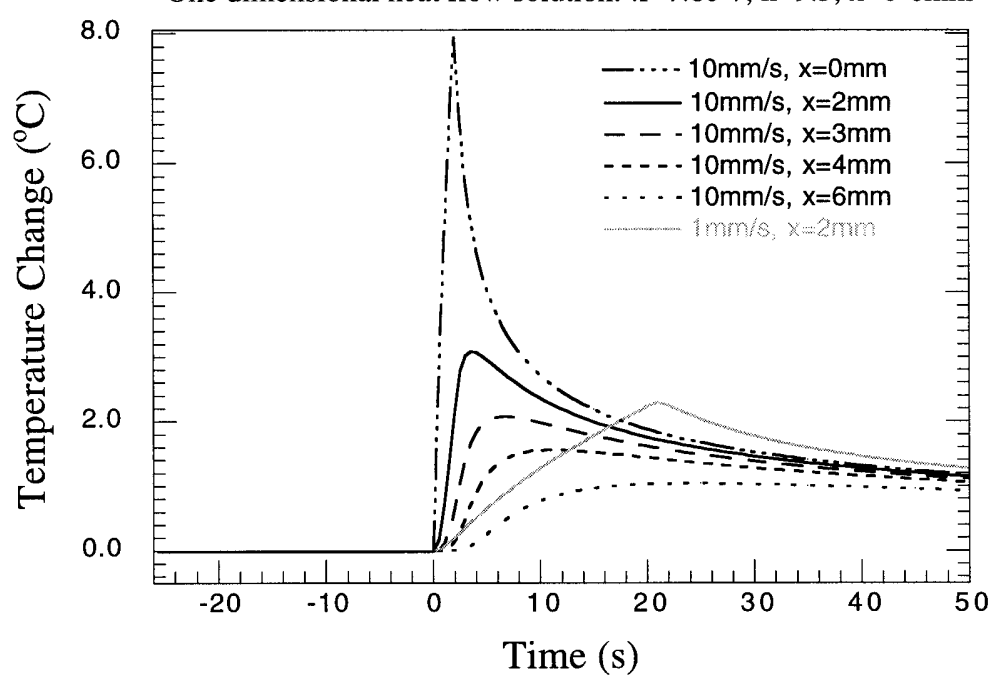

Figure 11

Temperature change versus time for shear heating within a layer of finite thickness $(2 \mathrm{~mm})$ using parameters documented in Table 2. These 1-D shear heating simulations are shown for the two velocities $V=1,10 \mathrm{~mm} / \mathrm{s}$, and $\sigma_{n}=25 \mathrm{MPa}$ for varying distances $(x)$ measured from the center of the granular layer. One simulation calculates the temperature change at the center of the $2 \mathrm{~mm}$ wide layer (i.e., $x=0$ $\mathrm{mm})$.

time in Figure 10. The main features of the data in Figure 6 are reproduced. Also apparent are the perturbations in temperature associated with individual velocity steps. Importantly, for a given test, these temperature perturbations gradually decrease in size with increasing displacement.

Figure 11 shows temperature rise versus time for a series of constant velocity simulations. The distance from the center of the fault zone $(x)$ is varied $(2-6 \mathrm{~mm})$ to simulate the temperature measured at different sensors. In addition, one simulation is run for the temperature rise expected at the center of the layer $(x=0 \mathrm{~mm})$. Heat production is constant during a time interval corresponding to $20 \mathrm{~mm}$ slip and is zero for all other times, comparable to experiments (Figs. 7, 8). Heating and cooling associated with the period of shear heating are shown in all curves. Maximum temperature decreases with the distance from the fault zone and the time required to reach maximum temperature increases systematically with distance. Results are qualitatively comparable to data presented in Figures 7, 8. The temperature change expected at the center of the layer is $\sim 8^{\circ} \mathrm{C}$. If the layer, where heat is produced, was thinner e.g., a shear band $\sim 0.1 \mathrm{~mm}$ thick as suggested from microstructural observations (Fig. $4 \mathrm{~b}$ ), temperature rise would instead be $\sim 12^{\circ} \mathrm{C}$.

The total temperature changes obtained from simulations of temperature change (at TC1) following $20 \mathrm{~mm}$ slip are plotted in Figure 12 (solid symbols) as a function of steady-state heat production. Experimental data (from TC1) for the relevant 


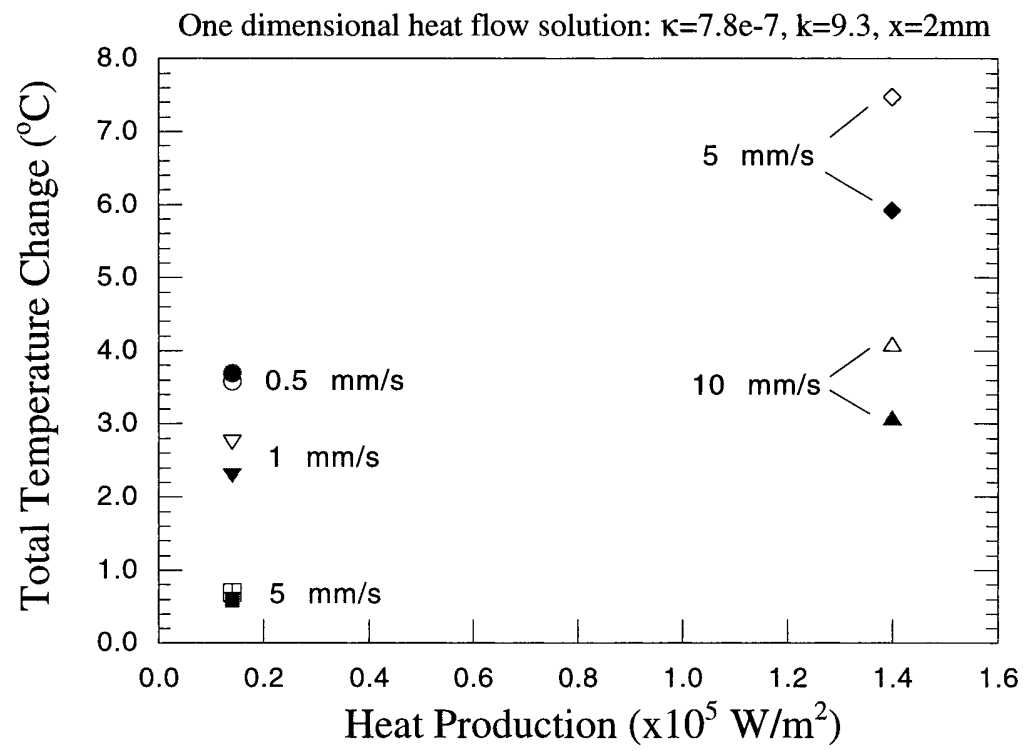

Figure 12

Total temperature change during $20 \mathrm{~mm}$ slip versus heat production $(q)$. Experimental data shown as open symbols for the conditions annotated. One-dimensional heat-flow solutions for the same conditions are indicated by the corresponding solid markers. Thermal properties used in the simulations are shown.

In general, the model approximates the data well.

conditions (open symbols) are superimposed. For a given heat production the temperature change is smaller for high velocity tests due to the finite time required for thermal diffusion through the sample. In general the one-dimensional heat flow results are in good qualitative agreement with our experimental data (Fig. 12). The agreement between the data and models is best for the low $q$ case, however the model underpredicts data for higher $q$. This likely due to the 1-D nature of the model. A more complex model would be required to fit other aspects of the data, however, given the focus here on the experimental data, additional modelling was considered beyond the scope of the current work.

\section{Discussion}

We have carried out experiments on granular layers over a wide range of conditions where we measure the quantities important in the heat production equation. Our study shows that temperature increases systematically as a function of both normal stress and sliding velocity, as observed previously in granular layers at lower normal stress conditions (LOCKNER and OKUBO, 1983) and on bare granite surfaces (BLANPIED et al., 1998; BROWN, 1998). We verify that the heat production equation holds for all tests. The conditions studied span regimes where 
deformation is interpreted to be dominated by very different mechanisms of grain fracture $\left(\sigma_{n} \geq 25 \mathrm{MPa}\right)$ and grain rolling $\left(\sigma_{n}=5 \mathrm{MPa}\right)$. Interestingly, heat production and temperature rise are comparable in both regimes. In addition, we investigate the influence of distributed versus localized slip. The degree of localization has no dramatic effect on heating. Moreover, we find no evidence for dramatic velocity weakening at high velocity or normal stress.

The main aspects of the temperature data for all our tests are well approximated by a simple one-dimensional heat-flow solution (Fig. 12). Importantly, tests at high and low normal stress can be described by the same heat-flow solution that lacks any complexities in microstructure. This indicates that the bulk thermal and mechanical properties of a granular layer are comparable irrespective of localization state or deformation regime. The data therefore imply that the frictional work done in shearing is equivalent whether the deformation regime is non-destructive (e.g., rolling) or involves the production of new surfaces through grain fracture. Hence we conclude that the energy dissipated due to new surface generation is minor compared to the overall work done, agreeing with the work of LOCKNER and OKuво (1983).

A possible alternative explanation is that energy is dissipated differently at low normal stress. In previous studies on bare surfaces (BLANPIED et al., 1998; BEELER et al., 1996), the work done due to fault dilation was essentially ignored since dilation was indeed minimal, however faults containing granular material show significantly larger dilation. If fault zone dilation is enhanced more at low normal stress as preliminary observations of granular layers suggest (MAIR and MARONE, manuscript in preparation), more work may be required to achieve this dilation. This energy could in theory compensate for the energy involved in grain fracture at high normal stress and alleviate the necessity that fracture is a minor energy sink. This model is speculative and clearly requires quantitative testing.

Our friction and microstructural data are consistent with previous observations (e.g., MARONE et al., 1990; BEELER et al., 1996) indicating that velocity strengthening is associated with distributed shear and velocity weakening is associated with localized deformation, respectively. An additional result is an association between a broad particle size distribution and localization (fracture regime, Fig. 4b) compared to a narrow range of grain sizes associated with distributed deformation (rolling regime, Fig. 4a). These observations correspond to a conceptual model based on numerical studies by MORGAN and BoetTCHER (1999) who propose that a broad grain size distribution (or larger number of grains) may assist shear localization due to a 'lubrication' effect of small grains acting as rollers. For a distribution of similarly sized grains (or a small number of grains) they anticipate the entire granular layer deforming by distributed shear.

Extrapolation of our laboratory results to natural fault systems is speculative due to differences in loading conditions, e.g., net slip. We can, however, directly 
compare our work to recent numerical studies investigating shear in granular layers for a similar range of conditions and deformation regimes (e.g., MoRA and PlACE, 1998, 1999). MORA and PlACE (1998) suggest significant weakening and reduced shear heating is associated with a switch from sliding to rolling mechanisms. In our experiments, we interpret grain rolling to be an important, perhaps the dominant deformation mechanism operating at low normal stress. However, we see no evidence for weakening or low heat production as proposed by Mora and Place (1998). This may indicate that grain rolling is not the sole deformation mechanism operating in our tests at low normal stress and that deformation is accommodated by a combination of rolling and sliding. MorA and Place (1999) state that the weakening observed in their numerical simulations is due to a self-organization process which appears to be localized slip. We show that dramatic weakening does not occur in our experiments for either localized or distributed slip. Thus, the particular self-organization processes thought to be responsible for weakening in the numerical experiments (MoRA and PlACE, 1999) may not be occurring in our laboratory tests. In summary, based on our study of shear heating in granular layers, we conclude that fault strength and heat flow are consistent with theoretical predictions for a wide range of slip velocities and effective stresses.

\section{Conclusions}

The heat production equation holds for all conditions studied for both localized and distributed shear. For a given $q$, the heat generated is similar in regimes where fracture and non-fracture are thought to dominate. The presence or absence of localized shear structures has little influence on heat production or temperature rise. If our results can be extrapolated to the San Andreas Fault, they would predict a strong fault with significant heating and hence additional mechanisms must operate to explain the heat-flow paradox.

\section{Acknowledgements}

We are grateful to U. Mok, S. Karner, K. Frye, N. Beeler and M. Blanpied for scientific discussions and technical expertise that benefited this study. N. Chatterjee provided help with the SEM work. We thank reviewers and editors for comments that improved the manuscript. This work was funded by National Science Foundation Grant EAR-9805327 and Petroleum Research Foundation Grant 33306-AC2. 


\section{REFERENCES}

Beeler, N. M., Tullis, T. E., Blanpied, M. L., and Weeks, J. D. (1996), Frictional Behavior of Large Displacement Faults, J. Geophys. Res. 101, 8697-8715.

Blanpied, M. L., Lockner, D. A., and Byerlee, J. D. (1995), Frictional Slip of Granite at Hydrothermal Conditions, J. Geophys. Res. 100, 13,045-13,064.

Blanpied, M. L., Tullis, T. E., and Weeks, J. D. (1998), Effects of Slip, Slip Rate and Shear Heating on the Friction of Granite, J. Geophys. Res. 103, 489-511.

Brown, S. R. (1998), Frictional Heating on Faults: Stable Sliding versus Stick Slip, J. Geophys. Res. 103, 7413-7420.

Cardwell, R. K., Chinn, D. S., Moore, G. F., and Turcotte, D. L. (1978), Frictional Heating on a Fault Zone with Finite Thickness, Geophys. J. R. Astron. Soc. 52, 525-530.

Chester, F. M., Evans, J. P., and Biegel, R. L. (1993), Internal Structure and Weakening Mechanisms of the San Andreas Fault, J. Geophys. Res. 98, 771-786.

Goldsby, D. L., and Tullis, T. E. (1998), Experimental Observations of Frictional Weakening During Large and Rapid Slip (Abstract), EOS Trans. AGU 79, Fall Meet. Suppl., F610.

Lachenbruch, A. T., and Sass, J. H. (1980), Heat Flow and Energetics of the San Andreas Fault Zone, J. Geophys. Res. 85, 6185-6222.

Lockner, D. A., and Okubo, P. G. (1983), Measurements of Frictional Heating in Granite, J. Geophys. Res. 88, 4313-4320.

Lockner, D. A., Summers, R., and Byerlee, J. D. (1986), Effects of Temperature and Sliding Rate on Frictional Strength of Granite, Pure appl. geophys. 124, 445-469.

Mair, K., and Marone, C. (1999a), Friction of Simulated Fault Gouge for a Wide Range of Velocities and Normal Stresses, J. Geophys. Res. 104, 28,899-28,914.

MaIr, K., and Marone, C. (1999b), Frictional and Microstructural Observations of Fault Gouge at High Velocity (Abstract), EOS Trans. AGU 80, Spring Meet. Suppl., S329.

Marone, C. (1998), Laboratory-derived Friction Laws and their Application to Seismic Faulting, Ann. Rev. Earth Planet. Sci. 26, 643-696.

Marone, C., and Kilgore, B. (1993), Scaling of Critical Slip Distance for Seismic Faulting with Shear Strain in Fault Zones, Nature 362, 618-621.

Marone, C., Raleigh, C. B., and Scholz, C. H. (1990), Frictional Behavior and Constitutive Modelling of Simulated Fault Gouge, J. Geophys. Res. 95, 7007-7025.

McKenzie, D. P., and Brune, J. N. (1972), Melting of Fault Planes during Large Earthquakes, Geophys. J. R. Astron. Soc. 29, 65-78.

Mora, P., and Place, D. (1998), Numerical Simulation of Earthquake Faults with Gouge: Toward a Comprehensive Explanation for the Heat-flow Paradox, J. Geophys. Res 103, 21,067-21,089.

Mora, P., and Place, D. (1999), The Weakness of Earthquake Faults, Geophys. Res. Lett. 26, 123-126.

Morgan, J. K., and Boettcher, M. S. (1999), Numerical Simulations of Granular Shear Zones Using the Distinct Element Method: I Shear Zone Kinematics and the Micromechanics of Localization, J. Geophys. Res. 104, 2703-2719.

SchOlZ, C. H. (1996), Faults without Friction, Nature 381, 556-557.

Scholz, C. H. (2000), Evidence for a Strong San Andreas Fault, Geology 28, 163-166.

Sibson, R. H. (1975), Generation of Pseudotachylytes by Ancient Seismic Faulting, Geophys. J. R. Astron. Soc. 43, 775-794.

Spray, J. G. (1993), Viscosity Determinations of Some Frictionally Generated Silicate Melts: Implications for Fault Zone Rheology at High Strain Rates, J. Geophys. Res. 98, 8053-8068.

STESKy, R. M. (1978), Rock Friction-Effect of Confining Pressure, Temperature and Pore Pressure, Pure appl. geophys. 116, 690-704.

Tsutsumi, A., and Shimamoto, T. (1997), High-velocity Frictional Properties of Gabbro, Geophys. Res. Lett. 24, 699-702.

Yoshioka, N. (1985), Temperature Measurements during Frictional Sliding of Rocks, J. Phys. Earth 33, $295-322$.

Yoshioka, N. (1986), Fracture Energy and the Variation of Gouge and Surface Roughness during Frictional Sliding of Rocks, J. Phys. Earth 34, 335-355.

(Received November 8, 1999, revised March 3, 2000, accepted April 15, 2000) 